\title{
Genetic diversity of banana bunchy top virus isolates from China
}

\author{
XUE-QIN RAO
}

\begin{abstract}
State Key Laboratory of Conservation and Utilization of Subtropical Agro-bioresources, Guangdong Province Key Laboratory of Microbial Signals and Disease Control, College of Agriculture, South China Agricultural University, Guangzhou, P. R. China
\end{abstract}

Received June 6, 2016; revised August 31, 2016; accepted March 31, 2017

\begin{abstract}
Summary. - Banana bunchy top virus (BBTV) (the genus Babuvirus, the family Nanoviridae) is a singlestranded circular DNA virus with a genome composed of six components designated as DNA-R, -U3, -S, -M, $-\mathrm{C}$, and $-\mathrm{N}$. This study analyzed the nucleotide identities of the DNA-R of 23 isolates from banana-producing provinces of China, including Guangdong, Hainan, Guangxi, and Yunnan. Results showed that the nucleotide identity of DNA-R was $72.3-100 \%$. Phylogenetic analysis indicated that these BBTV isolates were clustered in different subgroups within the Asian group (AG). Sequence analysis of the five other components (DNA -U3, $-\mathrm{S},-\mathrm{M},-\mathrm{C}$, and $-\mathrm{N}$ ) of the five isolates from China confirmed the results established for DNA-R of these BBTV isolates. This study suggested that the variation of DNA-R from Chinese BBTV isolates was considerably higher than the variation of other AG isolates, but their genetic diversity was low.
\end{abstract}

Keywords: banana; banana bunchy top virus; genetic diversity; phylogenetic analysis

\section{Introduction}

Banana bunchy top virus (BBTV, the genus Babuvirus, the family Nanoviridae) is isometric and contains six circular single-stranded DNA genome components (designated as DNA-R, -U3, -S, -M, -C, and -N), which encode the master replication initiation protein, a protein with unknown function, capsid protein, movement protein, cell cycle link protein, and nuclear-shuttle protein, respectively (Timchenko et al., 2000). Each component is monocistronic and encodes a single open reading frame (ORF), with the exception of DNA-R (Beetham et al., 1999). Previous studies categorized BBTV isolates from the South Pacific group (SPG) and Asian group (AG) on the basis of the gene sequence identity of the DNA-R (Hu et al., 2007). Given its multicomponent char-

*Corresponding author. E-mail: huaping@scau.edu.cn; phone: 086020-85281107. " The authors contributed equally to this work.

Abbreviations: $\mathrm{AG}=$ Asian group; $\mathrm{BBTD}=$ banana bunchy top disease; $\mathrm{BBTV}=$ banana bunchy top virus; $\mathrm{ORF}=$ open reading frame; $S P G=$ South Pacific group. acteristics, BBTV may undergo genetic recombination and reassortment (Hu et al., 2007; Stainton et al., 2015).

Banana (Musa spp.) is one of the important fruits in tropical and subtropical regions of China and is mainly grown in Guangdong, Guangxi, Yunnan, Fujian, and Hainan provinces. Banana bunchy top disease (BBTD), caused by BBTV, has become an important banana disease in China, the incidence of BBTD in recent years has ranged from approximately $70 \%$ to $80 \%$ in some old Chinese banana growing areas (Rao et al., 2013). Understanding the genetic diversity of BBTV is helpful to develop a reliable diagnosis and management strategies for BBTD. There are a few reported BBTV isolates in China (Feng et al., 2010; Stainton et al., 2015), most of the genetic diversity of BBTV isolates was analyzed based on DNA-R of BBTV. In this study, BBTV isolates were extensively investigated and collected from different provinces in China. The genetic diversity of these isolates was analyzed. This study performs a systematic analysis on six BBTV components of different isolates in China and comprehensively assesses the genetic diversity of DNA-R of the BBTV isolates, which will be helpful to understand the evolution of BBTV. 


\section{Materials and Methods}

Samples collection and BBTV detection. Thirty-nine banana leaf samples showing typical symptoms of BBTV were collected from Guangdong, Hainan, Guangxi, and Yunnan provinces of China from 2012 to 2013, as shown in Table 1, and kept in $-80^{\circ} \mathrm{C}$ freezer. Total DNA was extracted from banana leaves through the CTAB method (Dellaporta et al., 1983). The extracted DNA was then detected via endpoint PCR.

PCR amplification and cloning. PCR amplifications were performed using primers of Tian et al. (2004) and Feng et al. (2010) on a TaKaRa PCR Thermal Cycler under the following conditions: $98^{\circ} \mathrm{C}$ for $1 \mathrm{~min} ; 30$ cycles of $98^{\circ} \mathrm{C}$ for $15 \mathrm{~s}, 51-55^{\circ} \mathrm{C}$ for $15 \mathrm{~s}$, and $68^{\circ} \mathrm{C}$ for $1 \mathrm{~min}$; and an extension of $72^{\circ} \mathrm{C}$ for $10 \mathrm{~min}$. The PCR products were cloned into
pMD18-T (Takara, Dalian, China) in accordance with the manufacturer's instructions, and the recombinant plasmids were sequenced.

Genetic diversity and phylogenetic analyses. Multiple alignments and pairwise nucleotide identities of DNA-R sequences were carried out though MEGA software (Tamura et al., 2013). Phylogenetic analyses were conducted using the sequence alignments through the neighbor-joining algorithm with 1000 bootstrap replications, as implemented with the MEGA software version 6.0 (Tamura et al., 2013). Five isolates were selected for further analysis to determine the genetic diversity of the BBTV isolates across all components. These isolates were selected randomly from Guangdong, Guangxi, and Hainan provinces in China. The isolates, which were used for analysis in this study, are listed in Table 1.

Table 1. Details of BBTV isolates used in analyses obtained from GenBank and in this study

\begin{tabular}{|c|c|c|c|c|c|c|c|}
\hline Isolate & Source & Acc. No. & Group & Isolate & Source & Acc. No. & Group \\
\hline NSP & China & AF238875.1 & AG & Etawah & India & DQ656119.1 & SPG \\
\hline Guangdong-1 & China & AF246123.1 & AG & & India & EU140342.1 & SPG \\
\hline NS & China & AF238874.1 & AG & & India & AF416470.1 & SPG \\
\hline $\mathrm{C} 4$ & China & U97525.1 & AG & Bihar & India & FJ605506.1 & SPG \\
\hline Haikou-4 & China & HQ378190.1 & AG & Bangalore-GKVK & India & JN243751.1 & SPG \\
\hline DanZhouHD & China & GU559706.1 & AG & Andaman & India & EU531473.1 & SPG \\
\hline Haikou-4 & China & HQ378192.1 & AG & Lucknow & India & DQ256267.1 & SPG \\
\hline DanZhou & China & GU559705.1 & AG & & India & AY845437.1 & SPG \\
\hline Haikou-4 & China & HQ378191.1 & AG & & India & EU140341.1 & SPG \\
\hline Haikou-4 & China & HQ378193.1 & AG & Bihar & India & FJ605508.1 & SPG \\
\hline \multirow[t]{3}{*}{ Haikou-4 } & China & HQ378194.1 & AG & Lucknow & India & EU402601.2 & SPG \\
\hline & China:Taiwan & DQ826391.1 & AG & Bihar & India & FJ609644.1 & SPG \\
\hline & China:Taiwan & DQ826394.1 & AG & Bihar & India & FJ609642.1 & SPG \\
\hline \multirow[t]{2}{*}{ V-1 } & China:Taiwan & EF095165.1 & AG & Bihar & India & FJ609643.1 & SPG \\
\hline & China:Taiwan & DQ826395.1 & AG & Bangalore-GKVK & India & JN243752.1 & SPG \\
\hline \multirow[t]{2}{*}{$\mathrm{V}-1$} & China:Taiwan & EF095166.1 & AG & Bihar & India & FJ605507.1 & SPG \\
\hline & China:Taiwan & DQ826392.1 & AG & Bangalore-GKVK & India & JN243753.1 & SPG \\
\hline \multirow[t]{2}{*}{ V-1 } & China:Taiwan & EF095163.1 & AG & Bangalore-GKVK & India & JN243754.1 & SPG \\
\hline & China:Taiwan & DQ826393.1 & AG & Q553_LK_1995 & Sri Lanka & KM607680.1 & SPG \\
\hline \multirow[t]{2}{*}{ V-1 } & China:Taiwan & EF095164.1 & AG & KP5_LK_2003 & Sri Lanka & KM607656.1 & SPG \\
\hline & China:Taiwan & DQ826396.1 & AG & Kandy & Sri Lanka & JN250593.1 & SPG \\
\hline \multirow[t]{2}{*}{$\mathrm{V}-1$} & China:Taiwan & EF095162.1 & AG & Kandy & Sri Lanka & JN250594.1 & SPG \\
\hline & China:Taiwan & DQ826390.1 & AG & Kandy & Sri Lanka & JN250596.1 & SPG \\
\hline V-1 clone b & China:Taiwan & EF095161.1 & AG & Kandy & Sri Lanka & JN250597.1 & SPG \\
\hline TW3 & China:Taiwan & EU366169.1 & AG & Kandy & Sri Lanka & JN250598.1 & SPG \\
\hline Q623_TW_1996 & China:Taiwan & KM607684.1 & AG & Kandy & Sri Lanka & JN250595.1 & SPG \\
\hline JY3 & Japan & AB108457.1 & AG & clone mrep 2 & Pakistan & AM418534.1 & SPG \\
\hline JK3 & Japan & AB108453.1 & AG & TJ1 & Pakistan & AY996562.2 & SPG \\
\hline JM5 & Japan & AB108454.1 & $\mathrm{AG}$ & TJ3 & Pakistan & JX170762.1 & SPG \\
\hline JN4 & Japan & AB108452.1 & $\mathrm{AG}$ & $\mathrm{HD} 2$ & Pakistan & FJ859734.1 & SPG \\
\hline \multirow[t]{2}{*}{ bP5 } & Philippines & AB189067.1 & AG & clone mrep 3 & Pakistan & AM418536.1 & SPG \\
\hline & Philippines & AF416469.1 & AG & clone mrep jav & Pakistan & AM418538.1 & SPG \\
\hline aP34 & Philippines & AB250954.1 & $\mathrm{AG}$ & & Tonga & AF416467.1 & SPG \\
\hline
\end{tabular}


Table 1 (continued)

\begin{tabular}{|c|c|c|c|c|c|c|c|}
\hline Isolate & Source & Acc. No. & Group & Isolate & Source & Acc. No. & Group \\
\hline MS6_PH_2008 & Philippines & KM607666.1 & $\mathrm{AG}$ & TOS93_TO_2010 & Tonga & KM607721.1 & SPG \\
\hline IG33 & Indonesia & AB186924.1 & AG & Q570_TO_1990 & Tonga & KM607683.1 & SPG \\
\hline IJs11 & Indonesia & AB186926.1 & $\mathrm{AG}$ & 536_TO_1993 & Tonga & KM607600.1 & SPG \\
\hline BA-1 & Indonesia & AB847630.1 & AG & TOS28 & Tonga & JF957636.1 & SPG \\
\hline 520_ID_1995 & Indonesia & KM607593.1 & AG & Hawaiian & USA & U18077.1 & SPG \\
\hline \multirow{4}{*}{ V6 } & Viet Nam & AF416475.1 & AG & KP9_US_1990 & USA & KM607660.1 & SPG \\
\hline & Viet Nam & AB113659.1 & AG & 527_US_1992 & USA & KM607599.1 & SPG \\
\hline & Viet Nam & AF416474.1 & AG & & Egypt & AF416465.1 & SPG \\
\hline & Viet Nam & AF416472.1 & $\mathrm{AG}$ & Egyptian & Egypt & AF102780.1 & SPG \\
\hline $\mathrm{DDW}^{\star}$ & GD:Dongguang & KT215071 & AG & MY01 & Myanmar & AB252639.1 & SPG \\
\hline $\mathrm{DW}-1^{*}$ & GD:Guangzhou & KT215075 & AG & & Cameroon & GQ249344.1 & SPG \\
\hline $\mathrm{DW}-2^{*}$ & GD:Guangzhou & KT215076 & $\mathrm{AG}$ & & Fiji & AF416466.1 & SPG \\
\hline DN3-6* & GD:Zengcheng & KT215073 & AG & $\mathrm{DNN}^{*}$ & GD:Zengcheng & KT215074 & AG \\
\hline $\mathrm{XL}-2^{*}$ & GX:Longan & KT215084 & $\mathrm{AG}$ & HLM $^{*}$ & HN:Lingao & KT215080 & $\mathrm{AG}$ \\
\hline $\mathrm{XP}-2^{*}$ & GX:Pubei & KT215087 & AG & $\mathrm{XJ}-2^{*}$ & GX:Naning & KT215084 & AG \\
\hline $\mathrm{XSN}^{*}$ & GX:Naning & KT215088 & AG & HF-2* & HN:Chengmai & KT215079 & AG \\
\hline $\mathrm{XHD}^{*}$ & GX:Hepu & KT215083 & AG & YLJ-17* & YN:Baoshan & KT215090 & AG \\
\hline YLZ-3* & YN:Baoshan & KT215092 & AG & YLZ-4* & YN:Baoshan & KT215093 & AG \\
\hline YLM $^{*}$ & YN:Linpao & KT215091 & AG & HS- $1^{*}$ & HN:Sanya & KT215081 & AG \\
\hline $\mathrm{DW}-4^{*}$ & GD:Guangzhou & KT215077 & AG & $\mathrm{DW}-4^{*}(\mathrm{U} 3)$ & GD:Guangzhou & KX783438 & AG \\
\hline $\mathrm{DW}-4^{*}(\mathrm{~S})$ & GD:Guangzhou & KX779465 & AG & $\mathrm{DW}-4^{\star}(\mathrm{M})$ & GD:Guangzhou & KX779455 & AG \\
\hline $\mathrm{DW}-4^{*}(\mathrm{C})$ & GD:Guangzhou & KX779460 & $\mathrm{AG}$ & $\mathrm{DW}-4^{\star}(\mathrm{N})$ & GD:Guangzhou & KX787074 & $\mathrm{AG}$ \\
\hline $\mathrm{HF}-1^{*}$ & HN:Chengmai & KT215078 & AG & $\mathrm{HF}-1^{\star}(\mathrm{U} 3)$ & HN:Chengmai & KX783437 & AG \\
\hline $\mathrm{HF}-1^{*}(\mathrm{~S})$ & HN:Chengmai & KX779466 & $\mathrm{AG}$ & $\mathrm{HF}-1^{\star}(\mathrm{M})$ & HN:Chengmai & KX779456 & AG \\
\hline $\mathrm{HF}-1^{*}(\mathrm{C})$ & HN:Chengmai & KX779461 & AG & $\mathrm{HF}-1^{*}(\mathrm{~N})$ & HN:Chengmai & KX787073 & $\mathrm{AG}$ \\
\hline HS $-5^{*}$ & HN:Sanya & KT215082 & $\mathrm{AG}$ & $\mathrm{HS}-5^{*}(\mathrm{U} 3)$ & HN:Sanya & KX783436 & AG \\
\hline $\mathrm{HS}-5^{\star}(\mathrm{S})$ & HN:Sanya & KX779467 & AG & $\mathrm{HS}-5^{\star}(\mathrm{M})$ & HN:Sanya & KX779457 & AG \\
\hline $\mathrm{HS}-5^{*}(\mathrm{C})$ & HN:Sanya & KX779462 & AG & HS $-5^{*}(\mathrm{~N})$ & HN:Sanya & KX787072 & $\mathrm{AG}$ \\
\hline $\mathrm{XP}-1^{*}$ & GX:Pubei & KT215086 & $\mathrm{AG}$ & $\mathrm{XP}-1^{*}(\mathrm{U} 3)$ & GX:Pubei & KX783435 & AG \\
\hline $\mathrm{XP}-1^{*}(\mathrm{~S})$ & GX:Pubei & KX779468 & AG & $\mathrm{XP}-1^{*}(\mathrm{M})$ & GX:Pubei & KX779458 & AG \\
\hline $\mathrm{XP}-1^{*}(\mathrm{C})$ & GX:Pubei & KX779463 & AG & $\mathrm{XP}-1^{*}(\mathrm{~N})$ & GX:Pubei & KX787070 & $\mathrm{AG}$ \\
\hline $\mathrm{XTD}^{*}$ & GX:Naning & KT215089 & AG & XTD* (U3) & GX:Naning & KX783434 & AG \\
\hline $\mathrm{XTD}^{*}(\mathrm{~S})$ & GX:Naning & KX779469 & AG & $\mathrm{XTD}^{*}(\mathrm{M})$ & GX:Naning & KX779459 & AG \\
\hline $\mathrm{XTD}^{*}(\mathrm{C})$ & GX:Naning & KX779464 & AG & $\mathrm{XTD}^{*}(\mathrm{~N})$ & GX:Naning & KX787071 & AG \\
\hline DN3-1* & GD:Zengcheng & KT215072 & AG & & & & \\
\hline
\end{tabular}

Notes: AG: Asian group. SPG: South Pacific group. GD: Guangdong province of China; GX:Guangxi province of China. YN: Yunnan province of China. $\mathrm{HN}$ : Hainan province of China; ${ }^{*}$ : isolates in this study. (U3), (S), (M), (C), and (N) means different BBTV component, respectively, the others stand for DNA-R component of BBTV.

\section{Results and Discussion}

\section{BBTV detection via PCR}

PCR assays were performed with the primer set DNA1F/R (Tian et al., 2004) to detect BBTV in 39 suspected banana samples collected from Guangdong, Hainan, Guangxi, and Yunnan provinces of China. The DNA-R gene fragments of $1025 \mathrm{bp}$ were generated from 23 samples. Among them 4 were from Yunnan province, 7 from Guangxi province, 5 from Hainan province, and 7 from Guangdong province. The results suggested that these 23 banana samples were infected by BBTV.

Genetic diversity analysis of DNA-R of BBTV isolates from China

The DNA-R components of these 23 BBTV isolates were selected for genetic diversity analysis. Results showed that 


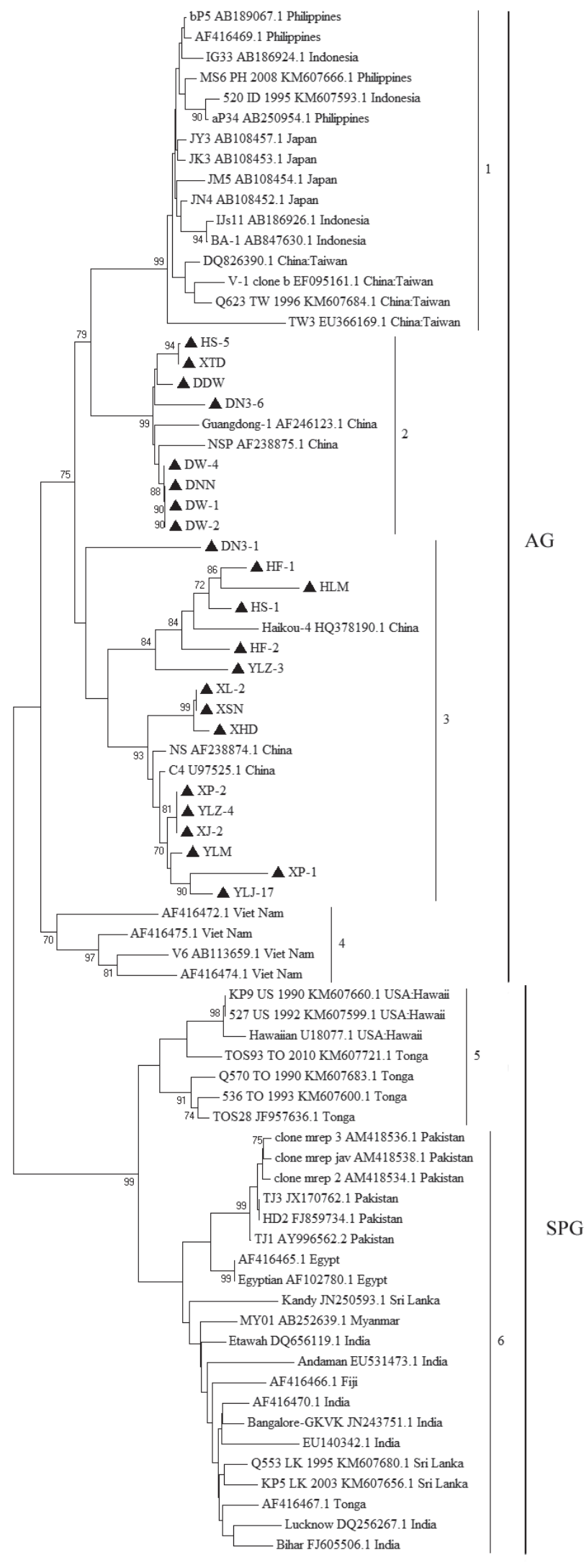

the isolates shared $72.3-100 \%$ identity at the nucleotide level. Compared among 23 BBTV isolates in this study, the nucleotide identity ranged from $86.0 \%$ to $100 \%$, most of them had $94.2-100 \%$ nt identity, while four isolates HF-1, HF-2, HS-5, and XP-1 shared 76.4-95\% nt identity with other BBTV isolates in this study, respectively. Compared with DNA-R of 53 BBTV isolates from GenBank, the results showed that the nucleotide identity ranged from $72.3 \%$ to 98.3\%, most of BBTV isolates shared $82.9-92.4 \%$ nt identity, while HS-5 and XP-1 had 72.3-80.8\% nt identity, HF-1 and HF-2 shared 91.2-98.3\% nt identity with those other BBTV isolates. These results showed that the maximum sequence variability of DNA-R was $14 \%$ among the 23 isolates from China. This value was considerably higher than those of the isolates from the AG (Stainton et al., 2015), which is different from the previously mentioned rates of BBTV divergence (Hu et al., 2007; Stainton et al., 2015).

\section{Phylogenetic analysis of the DNA-R of BBTV isolates from China}

Phylogenetic analysis of the DNA-R components of the 23 BBTV isolates in this study together with 53 BBTV isolates available from GenBank showed that these 76 BBTV isolates were clustered into two distinctive subgroups (Fig. 1), representing AG (Subgroups 1, 2, 3, and 4) and SPG (Subgroups 5 and 6), respectively. However, the 23 BBTV isolates in this study fell into two subgroups (Subgroups 2 and 3) in AG. Subgroup 2 consisted of 8 isolates in this study, 6 from Guangdong, one from Hainan, and one from Guangxi, respectively. Subgroup 3 comprised 15 isolates, 4 from Hainan, 4 from Yunnan, 6 from Guangxi, and one from Guangdong. Our results suggested that the BBTV isolates had distinct geographical distribution (Fig. 1), which is consistent with previous results (Yu et al., 2012; Banerjee et al., 2014).

Genetic diversity of DNA-U3, $-S,-M,-C$, and $-N$ of BBTV isolates from China

Isolates DW-4, HF-1, XP-1, XTD, and HS-5 were randomly selected for further analysis of the genetic diversity of DNA-U3, $-\mathrm{S},-\mathrm{M},-\mathrm{C}$, and $-\mathrm{N}$ to determine whether or not the analysis of these components supports the results of the

Fig. 1

Phylogenetic analysis of BBTV isolates based on nucleotide sequences of DNA-R components along with corresponding sequences of BBTV isolates available from GenBank

The isolates obtained in this study are indicated by " $\mathbf{\Delta}$ " (Table 1). The trees were constructed using the neighbor-joining method. The numbers at the nodes indicates bootstrap support (1,000 replicates). Values are shown only when the values are equal or greater than $70 \%$. 
(a)

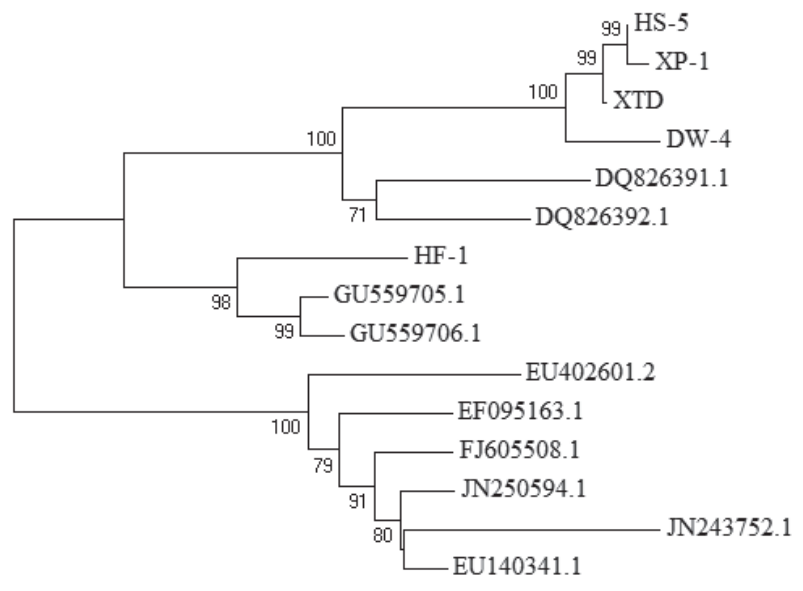

(c)

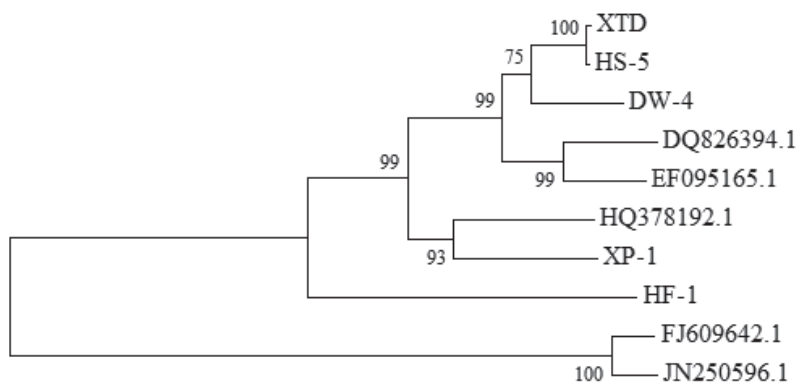

(e)

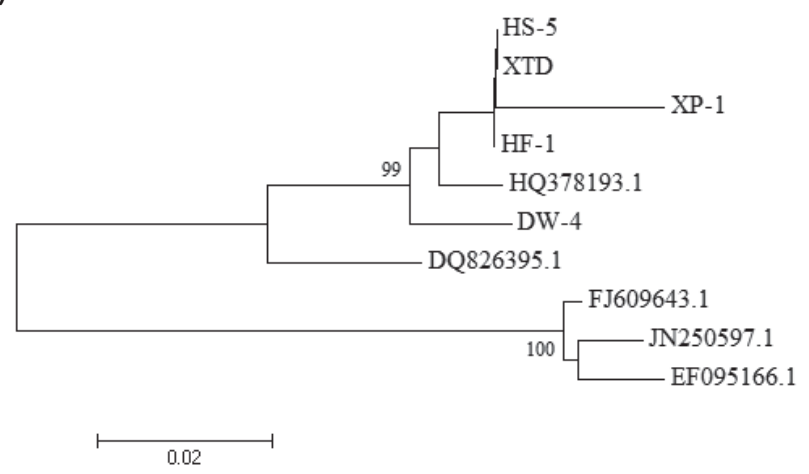

(b)
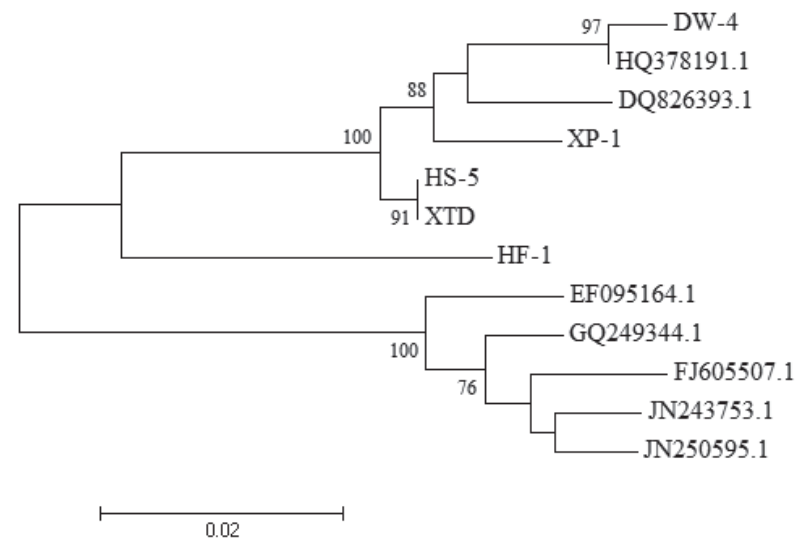

(d)

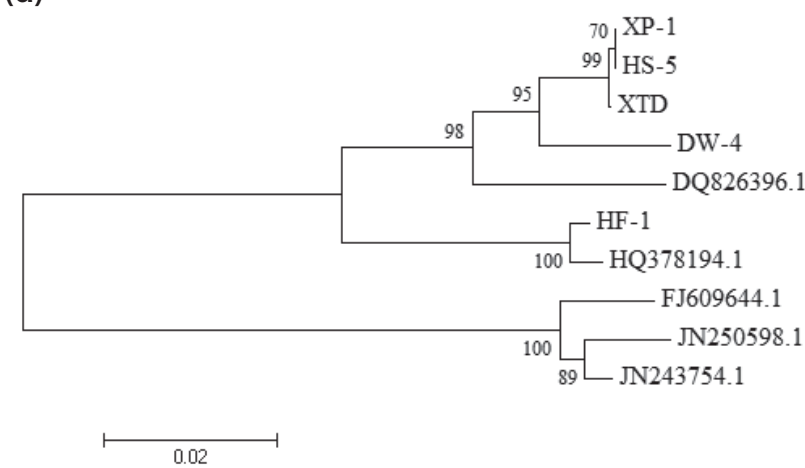

Fig. 2

Phylogenetic tree of the nucleotide sequences of BBTV DNA-U3 (a), -S (b), -M (c), -C (d), -N (e) components

The GenBank Acc. Nos. in this study are listed in Table 1. The trees were constructed using the neighbor-joining method. The numbers at the nodes indicate bootstrap support (1,000 replicates).

with Hainan isolates GU559705 and GU559706, and shared 77.8-85.4\% nt identity with other four isolates. Sequence analysis based on DNA-S showed that the nt identity among these isolates was $92.7-100 \%$, the phylogenetic analysis showed that these five isolates were clustered in the AG in two subgroups (Fig. 2b). According to DNA-M sequence analysis, the five isolates were clustered in the same subgroup

into three branches (Fig. 2c), the nt identity among these 5 analysis of BBTV isolates based on DNA-R. The nt identity of DNA-R of the five isolates was 87.2-99.7\%, and they were located in Subgroups 2 and 3 of the AG (Fig. 1). Phylogenetic analysis based on the gene sequences of DNA-U3 showed that the five isolates grouped with the Asian isolates (Fig. 2a), in which four isolates (HS-5, XP-1, XTD, and DW-4) shared 89.5-99.5\% nt identity and grouped with Taiwan isolates DQ826391 and DQ826392 (Fig. 2a), while HF-1 grouped 
isolates was 90.3-99.7\%. Analysis results of DNA-C showed that the five isolates were clustered in the same subgroup (Fig. $2 \mathrm{~d}$ ), the nt identity among these isolates was $97.2-100 \%$, and the nt identity of XP- 1 and HS- 5 was 100\%. Sequence analysis of DNA-N showed that the five isolates were clustered in the same subgroup (Fig. 2e), the nt identity among these isolates ranged from $93.4 \%$ to $99.9 \%$.

These results confirmed the sequence and phylogenetic analyses of BBTV DNA-R, which supported the geographical structuring of BBTV isolates (Hu et al., 2007; Yu et al., 2012). However, DNA-U3 was more variable (22.2\%) than other components of BBTV (2.8-14\%), which was caused by different evolutionary pressures on each component and/ or DNA component recombination in the genome of BBTV isolates (Hu et al., 2007; Hyder et al., 2011). Noticeably, DNA$\mathrm{U} 3$ in this study was detected the absence of an additional TATA box or a small ORF, this finding is opposite to previous reports (Yu et al., 2012), thereby emphasizing the additional components of DNA-U3. Significance of this observation is not known and warrants further investigation.

Although the genetic diversity of the BBTV isolates was reported (Hu et al., 2007; Banerjee et al., 2014), it was mostly assessed based on DNA-R or DNA-U3 of BBTV. The current study presented that the sequence data on the six components of the five BBTV isolates from China will be useful in future studies of these BBTV components.

Acknowledgements. The authors wish to acknowledge the Special Fund of China for Agro-Scientific Research in the Public Interest (201203076-07).

\section{References}

Banerjee A, Roy S, Behere GT, Roy SS, Dutta SK, Ngachan SV (2014): Identification and characterization of a distinct banana bunchy top virus isolate of Pacific-Indian oceans group from North-East India. Virus Res. 183, 41-49. https://doi.org/10.1016/j.virusres.2014.01.017
Beetham PR, Harding RM, Dale JL (1999): Banana bunchy top virus DNA-2 to -6 are mono cistronic. Arch. Virol. 144, 89-105. https://doi.org/10.1007/s007050050487

Dellaporta SL, Woods J, Hicks TB (1983): A plant DNA minipreparation: Version II. Plant Mol. Biol. Rep.1, 19-21. https:// doi.org/10.1007/BF02712670

Feng T, Wang J, Liu Z (2010): Cloning and sequencing of genome of banana bunchy top virus Haikou isolate. Acta Phytopathol. Sin. 40, 40-50.

Hu JM, Fu HC, Lin CH, Su HJ, Yeh HH (2007): Reassortment and concerted evolution in banana bunchy top virus genomes. J. Virol. 81, 1746-1761. https://doi.org/10.1128/JVI.01390-06

Hyder MZ, Shah SH, Hameed S, Naqvi SM (2011): Evidence of recombination in the Banana bunchy top virus genome. Infect. Genet. Evol. 11, 1293-1300. https://doi. org/10.1016/j.meegid.2011.04.015

Rao X, Sun J, Zhou L, Li H (2013): Banana virus disease prevention and control. China Fruit News 30, 74-76.

Stainton D, Martin DP, Muhire BM, Lolohea S, Halafihi M, Lepoint P, Blomme G, Crew K S, Sharman M, Kraberger S, Dayaram A, Walters M, Collings DA, Mabvakure B, Lemey P, Harkins GW, Thomas JE, Varsani A (2015): The global distribution of Banana bunchy top virus reveals little evidence for frequent recent, human-mediated long distance dispersal events. Virus Evol. 1, 1-16. https://doi. org/10.1093/ve/vev009

Tamura K, Stecher G, Peterson D, Filipski A, Kumar S (2013): MEGA6: molecular evolutionary genetics analysis version 6.0. Mol. Biol. Evol. 30, 2725-2729. https://doi. org $/ 10.1093 / \mathrm{molbev} / \mathrm{mst} 197$

Tian E, Zhuang J, Liu Z (2004): Cloning and sequencing of DNA Components of Banana bunchy top virus Hainan isolate. J. Agric. Biotechnol. 12, 680-684.

Timchenko T, Katul L, Sano Y, Kouchkovsky FD, Vetten HJ, Gronenborn B (2000): The master rep concept in nanovirus replication: identification of missing genome components and potential for natural genetic reassortment. Virology 274, 189-195. https://doi.org/10.1006/viro.2000.0439

Yu NT, Zhang YL, Feng TC, Wang JH, Kulye M, Yang WJ, Lin ZS, Xiong ZG, Liu ZX (2012): Cloning and sequence analysis of two banana bunchy top virus genomes in Hainan. Virus Genes 44, 488-494. https://doi.org/10.1007/s11262-012-0718-9 